\title{
A Study on Home Safety Practices to Prevent Childhood Injuries Among Mothers
}

\section{Shreedhara Avabratha Kadke, Sujatha Chunduri and Varadaraj Shenoy Kudpi}

Department of Paediatrics, Father Muller Medical College, Mangalore, Karnataka, India

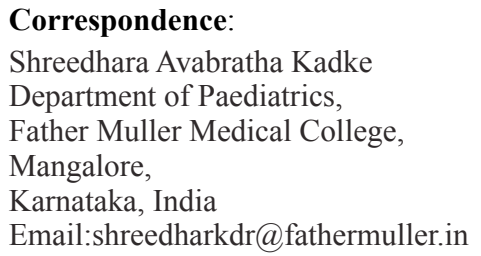

Shreedhara Avabratha Kadke

Department of Paediatrics,

Father Muller Medical College,

Mangalore,

Karnataka, India

Email:shreedharkdr@fathermuller.in

DOI: $10.3126 /$ jnps.v40i3.29375

Submitted on: 2020-06-08

Accepted on: 2020-10-02

Acknowledgements: None

Funding: Nil

Conflict of Interest: None declared

Permission from IRB: Yes

To cite this article: Kadke SA, Chunduri S, Kudpi VS. A Study on Home Safety Practices to Prevent Childhood Injuries Among Mothers. J Nepal Paediatr Soc. 2020;40(3):172-7.

\begin{abstract}
Introduction: Most unintentional injuries in children occur at home and many are preventable. Mothers and family's role in injury prevention is very important. We intended to study the role of home safety practices in prevention of childhood injuries.

Methods: This descriptive cross-sectional study was done using a questionnaire. Mothers of children aged one to five years were assessed about home safety practices to prevent childhood injuries. Questionnaire included personal data about the participants such as age, occupation, education, family size and number of children. Safety practices followed by mothers to prevent six types of injuries namely burn, cut, fall, drowning, poisoning and choking were noted.
\end{abstract}

Results: Of the 150 mothers interviewed, 104 were aged below 30 years, 88 were educated up to high school and 130 were housewives. Thirty mothers reported some kind of injury sustained by their children, of which twenty-one were falls. Among precautionary measures mother - behaviour safety initiatives e.g. checking the hot water temperature $(88 \%)$ or not leaving child alone $(92 \%)$ got better responses than passive or environmental modifications e.g. using electrical - outlet protection (44\%), staircase gates $(52 \%)$. Overall safety practices were reasonably good with the majority scoring above $50 \%$. Age, education, number of children, occupation of the mother, child age and history of injury did not correlate with the level of safety practices.

Conclusions: Mothers' home safety practices to prevent childhood injuries were relatively better in majority of the study population. Mother's age, educational level, occupation, number of children, child's age and history of injury did not affect how mother and her family practiced safety measures.

Keywords: Childhood; Injury; Mother; Safety practices

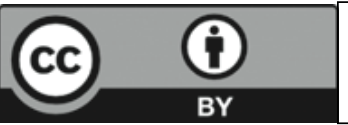

This work is licensed under creative common attribution 3.0 license 


\section{INTRODUCTION}

Childhood injury is a significant public health problem in terms of morbidity, mortality and lifelong disability. Children's characteristics make them more vulnerable for injuries. ${ }^{1,2}$ According to a report by UNICEF Innocenti Research Centre; injury is the second most common cause of death in children below five years of age. ${ }^{3}$ The prevalence of unintentional injuries among under five children varies from region to region; One South Indian study $^{4}$ showed 39\% whereas a study from $\mathrm{Nepal}^{5}$ showed 33\% prevalence. Injuries in children vary from motor car accidents to falls, burns, poisoning, drowning, choking and violence. ${ }^{6}$ Most unintentional injuries in children occur at home, due to the long duration spent at home, especially in small children and the numerous potential hazards being present at home. ${ }^{7}$ Maternal stress and education are other indirect factors of paediatric unintentional domestic injuries. ${ }^{8}$ Many of the childhood injuries are preventable which can be prevented by mother and the family. This study thus aims for the evaluation of mother's and family practices in the aspect of prevention of childhood unintentional injuries.

\section{METHODS}

This descriptive cross sectional study was done using a questionnaire. Mothers of children aged one to five years were assessed about home safety practices to prevent childhood injuries, when they attended the Paediatric outpatient and inpatient Departments of Fr. Muller Medical College Hospital, Mangalore, India. Mothers of children aged less than one year or more than five years, those unwilling to participate and with psychiatric illness were excluded. Sample size was estimated to be 130 , using the formula $Z \alpha^{2} \mathrm{p}(1-\mathrm{p}) / \mathrm{e}^{2}$ where $\mathrm{Z} \alpha=1.96 @ 95 \% \mathrm{CI}, \mathrm{p}=31.6 \%{ }^{9}, \mathrm{e}=8 \%$ allowable error. Rounding off, one hundred and fifty mothers were included in the study. Simple random sampling technique was used. Study duration was two months. Data were collected utilising a specifically designed structured questionnaire, based on available literature on this subject ${ }^{10}$ after validating with a senior paediatrician. The questionnaire was made in English as well as in the local language. The questionnaire also included personal data about the participants like age, occupation, education, family size and number of children. Safety practices followed by mothers to prevent six different types of injuries namely burn, cut, fall, drowning, poisoning and choking were noted down. Informed consent was obtained from the mothers after assuring complete confidentiality. Participants were informed of the aims of the study which were to ascertain what were and were not safety practices in their home environment with respect to prevention of childhood injuries. They were also told that the researcher did not expect them to practise all the safety measures covered in the study. Good practice response was given a score of 1 and wrong practice was given a 0 score. Institutional ethical committee approved the study. The collected data were tabulated and analysed statistically using frequency, percentage and Chisquare test.

\section{RESULTS}

A total of 150 mothers were interviewed. Demographic characteristics of the study participants are shown in Table 1.

Table 1. Demographic characteristics $(n=150)$ dimensions $(\mathrm{cm})$

\begin{tabular}{|cr|}
\hline Characteristic & Number (\%) \\
\hline Mother's age & \\
$<20$ years & $01(0.7)$ \\
20 - 30 years & $103(68.7)$ \\
$>30$ years & $46(30.6)$ \\
Mother's education & \\
Primary & $31(20.7)$ \\
High school & $88(58.7)$ \\
Degree & $26(17.3)$ \\
Post graduate & $05(03.3)$ \\
Mother's occupation & \\
Housewife & $130(86.7)$ \\
Working & $20(13.3)$ \\
Number of children & \\
1 & $36(24.0)$ \\
2 & $69(46.0)$ \\
More than 2 & $45(30.0)$ \\
Child's age & \\
1 - $<2$ years & $62(41.3)$ \\
2 - 5 years & $88(58.7)$ \\
History of injury & $30(20.0)$ \\
Yes & $120(80.0)$ \\
No &
\end{tabular}


Table 2. Safety practices and mothers' responses

\begin{tabular}{|c|c|c|c|c|}
\hline & Questions on practice & $\begin{array}{l}\text { Wrong } \\
\text { practice }\end{array}$ & $\begin{array}{c}\text { Right } \\
\text { practice }\end{array}$ & NA \\
\hline Burn & $\begin{array}{l}\text { 1. Safety plugs on electrical outlets } \\
\text { 2. Check hot water temp before bath } \\
\text { 3. Drink hot beverages with child on lap } \\
\text { 4. Carry hot food when child is nearby } \\
\text { 5. Turn handles of vessels to back of stove }\end{array}$ & $\begin{array}{l}84(56.0) \\
18(12.0) \\
42(28.0) \\
08(05.3) \\
85(56.7)\end{array}$ & $\begin{array}{r}66(44.0) \\
132(88.0) \\
108(72.0) \\
142(94.7) \\
65(43.3)\end{array}$ & \\
\hline Cut & $\begin{array}{l}\text { 6. Keep sharp objects out of reach of child } \\
\text { 7. Leave child alone in a room with breakable objects } \\
\text { 8. Avoid children carrying breakables } \\
\text { 9. Garbage can out of reach of child }\end{array}$ & $\begin{array}{l}32(21.3) \\
12(08.0) \\
57(38.0) \\
37(24.7)\end{array}$ & $\begin{array}{r}118(78.7) \\
138(92.0) \\
93(62.0) \\
113(75.3)\end{array}$ & \\
\hline Fall & $\begin{array}{l}\text { 10. Safety railing for high bed } \\
\text { 11. Safety gates on the stairs } \\
\text { 12. Keep child alone on a table top } \\
\text { 13. Allow child sit on countertop while cooking } \\
\text { 14. Have anything around that child could climb \& fall off } \\
\text { 15. Allow to climb stairs unattended } \\
\text { 15. Balconies are protected (if lives in flat) }\end{array}$ & $\begin{array}{l}85(56.7) \\
65(43.3) \\
19(12.7) \\
17(11.3) \\
34(22.7) \\
39(26.0) \\
25(16.7)\end{array}$ & $\begin{array}{r}64(42.7) \\
78(52.0) \\
131(87.3) \\
133(88.7) \\
116(77.3) \\
105(70.0) \\
70(46.7)\end{array}$ & $\begin{array}{r}06(4.0) \\
55(36.7)\end{array}$ \\
\hline Drowning & $\begin{array}{l}\text { 17. Empty water buckets after use } \\
\text { 18. Leave child alone having bath } \\
\text { 19. Leave child alone near pool, lake, well or on beach } \\
\text { 20. Let child play in bucket full of water, alone } \\
\text { 21. Keep toilet lids closed / bathroom door closed }\end{array}$ & $\begin{array}{l}37(24.7) \\
05(03.3) \\
05(03.3) \\
10(06.7) \\
40(26.7)\end{array}$ & $\begin{array}{l}113(75.3) \\
145(96.7) \\
145(96.7) \\
140(93.3) \\
110(73.3)\end{array}$ & \\
\hline Poisoning & $\begin{array}{l}\text { 22. Store medications out of reach of child } \\
\text { 23. Store phenol etc. out of child's reach } \\
\text { 24. Have poisonous plants around }\end{array}$ & $\begin{array}{l}17(11.3) \\
17(11.3) \\
16(10.7)\end{array}$ & $\begin{array}{l}133(88.7) \\
133(88.7) \\
134(89.7)\end{array}$ & \\
\hline Choking & $\begin{array}{l}\text { 25. Keep child away from toys that have small pieces } \\
26 \text {. Keep plastic bags out of child's reach }\end{array}$ & $\begin{array}{l}40(26.7) \\
52(34.7)\end{array}$ & $\begin{array}{r}110(73.3) \\
98(65.3)\end{array}$ & \\
\hline
\end{tabular}

Thirty mothers reported some kind of injury sustained by their children, of which fall from the bed topped the list. Twenty-one were falls, four were consumption of kerosene / floor cleaner, three were thermal (hot water / tea, bike silencer) injury, one was electric shock and one was cut injury. Among precautionary measures (Table 2) mother behaviour safety initiatives e.g. checking the hot water temperature $(88 \%)$ or not leaving the child alone $(92 \%)$ got better responses than passive or environmental modifications e.g. using electrical outlet protection (44\%), staircase gates (52\%).

Table 3. Overall safety practices

\begin{tabular}{|lr|}
\hline Practice -performance & Frequency (\%) \\
\hline Poor $(<50 \%$ right practice) & $04(02.7)$ \\
Moderate $(50-75 \%)$ & $68(45.3)$ \\
Good $(>75 \%)$ & $78(52.0)$ \\
Total & $150(100.0)$
\end{tabular}

Overall safety practices were reasonably good (Table 3) with majority scoring above 50\%. Age, education, number of children, occupation of the mother, child age and history of injury did not correlate with the level of safety practices (Table 4).

\section{DISCUSSION}

Injury is defined as any unintentional damage to any part of the body. ${ }^{1}$ Children are prone to injuries and most of those injuries are accidental. There are many contributing factors and some of them are preventable. As younger children spend most of the time at home, mothers' role in injury prevention is vital. In this background, the present study becomes important as it evaluates mothers' practices in preventing different types of injuries. Our study population comprised of relatively young mothers (69.4\% below 30 years), reasonably educated and more than $85 \%$ were staying at home. This increases the strength of our study as majority were 
Table 4. Correlation of demographic characteristics of mothers with levels of practice

\begin{tabular}{|c|c|c|c|c|c|c|c|}
\hline \multirow[t]{3}{*}{ Characteristics } & \multicolumn{7}{|c|}{ Overall practice } \\
\hline & \multicolumn{2}{|c|}{ Poor practice } & \multicolumn{2}{|c|}{ Moderate practice } & \multicolumn{2}{|c|}{ Good practice } & \multirow{2}{*}{$\begin{array}{c}\begin{array}{c}\text { Chi square/ } \\
\text { Fishers exact test }\end{array} \\
\text { p-value }\end{array}$} \\
\hline & Count & Row \% & Count & Row \% & Count & Row \% & \\
\hline Mother's age & & & & & & & 0.811 \\
\hline$<20$ years & 0 & 0.0 & 0 & 0.0 & 01 & 100.0 & \\
\hline $20-30$ years & 03 & 02.9 & 49 & 47.6 & 51 & 49.5 & \\
\hline$>30$ years & 0 & 0.0 & 19 & 42.2 & 26 & 57.8 & \\
\hline Mother's education & & & & & & & 0.222 \\
\hline Primary & 01 & 03.3 & 14 & 46.7 & 15 & 50.0 & \\
\hline High school & 01 & 01.1 & 42 & 47.7 & 45 & 51.1 & \\
\hline Degree & 0 & 0.0 & 11 & 42.3 & 15 & 57.7 & \\
\hline Post graduate & 01 & 20.0 & 01 & 20.0 & 03 & 60.0 & \\
\hline Number of children & & & & & & & 0.294 \\
\hline 1 & 01 & 02.9 & 16 & 45.7 & 18 & 51.4 & \\
\hline 2 & 01 & 01.4 & 36 & 52.2 & 32 & 46.4 & \\
\hline More than 2 & 01 & 02.2 & 16 & 35.6 & 28 & 62.2 & \\
\hline Mother's occupation & & & & & & & 0.209 \\
\hline Housewife & 02 & 01.6 & 62 & 48.1 & 65.0 & 50.4 & \\
\hline Working & 01 & 05.0 & 06 & 30.0 & 13.0 & 65.0 & \\
\hline Child's age & & & & & & & 0.209 \\
\hline $1-<2$ years & 02 & 03.2 & 23.0 & 37.1 & 37 & 59.7 & \\
\hline $2-5$ years & 01 & 01.1 & 45.0 & 51.7 & 41 & 47.1 & \\
\hline History of injury & & & & & & & 0.254 \\
\hline Yes & 02 & 06.7 & 14 & 46.7 & 14 & 46.7 & \\
\hline No & 01 & 0.8 & 15 & 45.4 & 64 & 53.8 & \\
\hline
\end{tabular}

with their kids at home, responsible for injury prevention.

Thirty mothers reported some kind of injury sustained by their children, fall from height topping the list. However, there was no report of any permanent disability due to injury. Falls were common causes of injury in other studies. ${ }^{1}$ In a survey done in Central India, ${ }^{11}$ accidental injuries due to non fatal falls at home had an incidence of $7.8 \%$. Morrongiello BA et al states that more than four million pre-schoolers are injured yearly, mostly in their homes. ${ }^{10}$

Regarding precautionary measures taken by parents about injury risks at home, some parents had better responses than others. Of course there was no expectation that any parent will take all precautions listed in the questionnaire. In passive surveillance for childhood injuries trivial injuries may not get reported. ${ }^{12}$ There are considerable variations in mothers' practices. The measures at mother's level like checking hot water temperature, not leaving child alone, storing medications out of reach etc. got better responses. Using safety plugs on electrical outlets, safety railing for high bed, safety gates on the stairs had lesser responses. Possibly, some of them involve additional cost for modifications or are not in their hands. It is also possibly related to lack of awareness amongst the parents. It may also imply mothers or family's perception that burns and drowning are more serious than preventing falls. Some may even think that falling is natural during development. ${ }^{13}$

Overall safety practices were good in our study, though there is scope for improvement. Majority scored more than 50\%. When level of safety practices was correlated with age, education, number of children, occupation of the mother, child age and history of injury, none of them significantly correlated. However, a study by Ray K et al. found 
correlation with mother's education and number of children. ${ }^{1}$ We cannot know how accurately mothers reported on safety practices. However, mothers were told clearly in the beginning that they need not say yes for all good practices and that was not the intention of the study. Furthermore, we cannot be complacent about the findings of this study. There are lacunas and outcomes can be catastrophic. Better health education on safety measures is needed to prevent injuries and to improve the standards and quality of life of children. There are studies, which have shown significant improvements in mothers' knowledge after educational sessions. ${ }^{14}$

\section{CONCLUSIONS}

Mothers' home safety practices to prevent childhood injuries were relatively good in our study population. However, there is a need of ongoing education and vigilance from families in order to prevent or alleviate childhood injuries. Mother's age, educational level, occupation, number of children, child's age and history of injury did not affect how our parents adopt practices to prevent injuries in children.

\section{REFERENCES}

1. Ray K, Bhattacherjee S, Akbar F, Biswas R, Banerjee R, Chakraborty M. Physical Injury: A profile among the municipal primary school children of Siliguri, Darjeeling District. Ind J Public Health. 2012;56:49-52. DOI: 10.4103/0019-557x.96972

2. Verma S, Lal N, Lodha R, Murmu L. Childhood trauma profile at a tertiary care hospital in India. Indian Pediatr 2009;46:168-71. PMID: 19242037

3. Linnan M, Giersing M, Cox R, Linnan H, Williams MK, Voumard C, et al. Child mortality and injury in Asia, an overview. Florence: UNICEF Innocenti Research Centre; 2007:26. (Innocenti Working Paper no 2007-07; special series on child injury no 4 ).

4. Sharma S, Reddy N S, Ramanujam K, Jennifer M, Gunasekaran A, Rose A, et al. Unintentional injuries among children aged 1-5 years: understanding the burden, risk factors and severity in urban slums of southern India. Injury Epidemiology. 2018; 5(1). DOI: 10.1186/s40621-018-0170-y

5. Kafle B, Yadav U, Marahatta S, Mishra D, Pant N. Unintentional Injuries among Under-Five Children in MidWestern Nepal. J Nepal Paediat Soc. 2018; 38(1):46-52. DOI: https://doi.org/10.3126/jnps.v38i1.18250

6. CDC childhood injury report: Patterns of unintentional injuries among 0-19 year olds in the United States, 20002006.

7. Hyder AA, Sugerman DE, Puvanachandra P, Razzak J, EI-Sayed H, Isaza A, et al. Global childhood unintentional injury surveillance in four cities in developing countries: a pilot study. Bulletin of the World Health Organisation 2009;87(5): 345-52. DOI:10.2471/blt.08.055798

8. Damashek AL, Williams NA, Sher KJ, Peterson L, Lewis T, Schweinle W. Risk for minor childhood injury: An investigation of maternal and child factors. J Pediatr Psychol. 2005;30(6): 469-80. DOI: 10.1093/jpepsy/jsi072

9. Adhikari B, Bhattarai S, Gauro P, Mishra R. Awareness and practice of mother having under five children regarding prevention of childhood accident. Int J Health Sci Res. 2017;7(9):134-144.

10. Morrongiello BA, Kiriakou S. Mothers' home safety practices for preventing six types of childhood injuries; What they do and why? J Pediatr Psychol. 2004;29(4):285-97. DOI: 10.1093/jpepsy/jsh030

11. Pathak A, Agarwal N, Mehra L, Mathur A, Diwan V. Incidence, risk and protective factors for unintentional, nonfatal, fall-related injuries at home: A community-based household survey from Ujjain, India. Pediatric Health Med Ther. 2020;11:65-72. DOI: https://doi.org/10.2147/PHMT.S242173

12. Sivamani M, Balraj V, Muliyil J P. Validity of a surveillance system for childhood injuries in a rural block of Tamilnadu. Indian J Community Med. 2009;34:43-7. DOI:10.4103/0970-0218.44650

13. Morrongiello BA, Dayler L. A community-based study of parents' knowledge, attitudes and beliefs related to childhood injuries. Can J Public Health. 1996;87(6):383-8. PMID: 9009394 
14. Megahed MA, Khalil NA, Ibrahem RA, El Disoki RS. Knowledge, attitude and practice of rural mothers towards home injuries among children under 5 years of age in Menouf District- Menoufia Governorate, Egypt. Menoufia Med J. 2016;29(4):1033-9. DOI: 10.4103/1110-2098.202506 